\title{
Choosing ultrasound technique for suspected deep vein thrombosis: which is best?
}

\author{
Scott M. Stevens ${ }^{1,2}$, Masarret Fazili ${ }^{1}$, Scott C. Woller ${ }^{1,2}$ \\ ${ }^{1}$ Intermountain Healthcare, Murray, UT, USA; ${ }^{2}$ School of Medicine, University of Utah, Murray, UT, USA \\ Correspondence to: Scott M. Stevens, MD. Intermountain Healthcare, 5169 South Cottonwood Street, Suite 300, Murray, UT 84107, USA. \\ Email: Scott.StevensMD@imail.org.
}

Provenance and Peer Review: This article was commissioned by the editorial office, Quantitative Imaging in Medicine and Surgery. The article did not undergo external peer review.

Comment on: Kraaijpoel N, Carrier M, Le Gal G, McInnes MDF, Salameh JP, McGrath TA, van Es N, Moher D, Büller HR, Bossuyt PM, Leeflang MMG. Diagnostic accuracy of three ultrasonography strategies for deep vein thrombosis of the lower extremity: a systematic review and metaanalysis. PLoS One 2020;15:e0228788.

Submitted Apr 28, 2020. Accepted for publication May 19, 2020.

doi: 10.21037/qims-2020-18

View this article at: http://dx.doi.org/10.21037/qims-2020-18

Deep vein thrombosis (DVT) is a prevalent disease which, if left untreated, can be complicated by pulmonary embolism (PE) and enduring leg maladies (a compendium of symptoms referred to as post-thrombotic syndrome) among other associated morbidities (1). Prompt and accurate diagnosis of DVT is essential. Contrast venography, considered the reference standard for the diagnosis of DVT, is invasive, expensive, technically challenging and is now performed infrequently. Compression ultrasonography (CUS) has become the most commonly used imaging method to evaluate suspected DVT of the leg (2).

CUS is non-invasive, carries no risk of radiation or contrast exposure, and is relatively inexpensive. DVT is diagnosed by observing a region of non-compressibility of a deep vein when pressure is applied using the ultrasound probe during imaging (the presence of thrombus prevents the vein from fully compressing). Additional techniques, such as color doppler flow analysis (duplex ultrasound) can be added to assist in identifying areas to test for noncompressibility (3).

Older accuracy studies directly compared the performance of CUS to invasive venography. CUS had comparable sensitivity and specificity to venography for proximal DVT, but was less sensitive in detecting distal
DVT (4). However, substantial technologic advances in US have been made since these studies were performed. Contemporary research has utilized the "management study" design, where treatment decisions are based on CUS result, and patients are monitored for outcome over the subsequent 3 months (any DVT or PE diagnosed during follow-up is assumed to have been missed by the initial diagnostic strategy) (2).

The term "CUS" has been applied to a variety of diagnostic techniques (5). The most important distinction between techniques regards whether the distal deep veins (the deep veins of the calf below the popliteal vein) are assessed. Most DVT originates in these veins. DVT isolated to the distal deep veins (IDDVT) carries a low risk of PE and post-thrombotic syndrome; and many cases will resolve without anticoagulant treatment (6). However, IDDVT may propagate upward to become proximal DVT, which is associated with a substantial risk of $\mathrm{PE}$, post-thrombotic syndrome, and requires treatment with anticoagulants (7).

The uncertain value of detecting IDDVT has led to a longstanding controversy regarding the ideal approach to imaging (8). Whole-leg CUS refers to the technique which assesses the distal deep veins (9). The value of this test is its high negative predictive value excluding any DVT in 
a single session even among patients with a high pre-test probability (PTP) of disease (10). The principal limitation of the technique is that a management decision must be made when IDDVT is detected, and it is uncertain which of these patients require treatment with anticoagulants (11). The benefits of treatment remain uncertain, and may differ between patient groups (such as those with cancer or an assessed increased risk for bleeding).

Limited CUS assesses only the proximal deep veins (12). Interinstitutional technique varies in the procedure and number of locations assessed however all share the feature of assessing only the popliteal and more proximal veins. The advantaged of limited CUS include technical simplicity and the fact that it only detects DVT that requires anticoagulant treatment. The principal disadvantage is reduced negative predictive value, which has led to protocols endorsed by guidelines that require a repeat test to be performed 5-7 days later to detect undiagnosed IDDVT which has propagated (serial limited CUS) $(2,13)$. Repeat testing is inconvenient and not all patients are able to return for serial tests. Further, a large number of serial tests must be performed to detect relatively few DVTs (low diagnostic yield) (5).

Regardless of the CUS used, only a small minority of patients suspected of DVT are proven to have it (14). Therefore, multi-step diagnostic algorithms have been developed to try to reduce the number of patients subjected to imaging (2). Many such algorithms exist, but all are based on Bayes' Theorem, and attempt to identify a subgroup of patients with a likelihood of DVT low enough that imaging is not needed. The algorithms utilize a PTP score based on elements from patients' history and examination, in combination with measurement of D-dimer, an inexpensive laboratory assay which measures thrombus breakdown products, to identify patients in whom DVT can be safely excluded without imaging. There is presently no strategy that can confirm DVT without an imaging test (13).

An interesting hybrid approach has tested whether patients at intermediate levels PTP of DVT can have disease safely excluded with only one a single limited CUS; eliminating the need for the second US, but also bypassing the problem of management of IDDVT (2).

A prior systematic review assessed the performance of a single whole-leg CUS versus serial CUS in unselected patients, pooling available management studies. The safety of both approaches was comparable; whole-leg US diagnosed IDDVT leading to a greater number of patients on anticoagulant therapy. Serial limited CUS resulted in a larger total number of CUS sessions (9).

Kraaijpoel and colleagues recently published a new systematic review and meta-analysis that includes more recent management studies, and adds an analysis of the comparative performance of single limited CUS to both serial limited CUS and whole-leg CUS (15). The "failure" rate (percentage of DVT or PE 90 days after an initial negative evaluation) was $1.4 \%$ for single limited CUS, $1.9 \%$ for serial limited CUS and 1.0\% for whole-leg CUS.

The work is nicely executed, adhering well to the methodologic standards for the PRISMA checklist for metanalyses of diagnostic trials. Strengths include study selection, data abstraction and risk of bias assessment performed in triplicate, and use of the most recent Quality Assessment of Diagnostic Accuracy Studies (QUADAS-2) tool.

Conclusions from the analysis must be drawn with an appreciation of the complexity of the underlying trial designs, as the authors note: "The relative failure rate of single limited CUS remains uncertain, as the DVT prevalence was lower in these studies. Therefore, this CUS strategy may only be safe in a selected group of low-risk patients". Despite the similar failure rates, concluding that all three approaches to CUS are interchangeable is inappropriate.

The more recent management studies utilizing the three different approaches to CUS have evaluated CUS as only one component of a larger diagnostic algorithm. Patients undergoing CUS were first assessed using a variety of PTP scores in combination with D-dimer. Therefore, the different forms of CUS will have been applied to differing patient populations, which complicates direct comparison of their performance $(2,13)$.

For these comparisons the authors included both management studies, as well as accuracy studies versus venography in their analyses. This approach has advantages and disadvantages. Including accuracy studies enlarges the number of trials and increases the precision of estimates. However, accuracy studies operate on the a priori supposition that the reference test (venography) is $100 \%$ sensitive and specific. In fact, venography has been tested in a management study, and was found to have a 90-day "failure" rate of approximately $2 \%$, creating the standard by which diagnostic management studies are assessed in major guidelines $(2,16)$. Therefore, pooling the performance of CUS versus venogram, as opposed to clinical follow-up, makes interpretation of results more difficult.

What conclusions can be drawn from the work of Kraaijpoel and colleagues? Their findings appear to lend 
further support to the recommendations made in the American Society of Hematology 2018 guidelines for management of venous thromboembolism: diagnosis of venous thromboembolism (13). These guidelines endorse the importance of assessment of PTP and use of D-dimer testing, in addition to imaging, when DVT is suspected. When imaging is indicated in patients in the low-PTP group, either single limited CUS or whole-leg CUS are acceptable. If PTP is not low, single limited CUS is not sufficient-serial limited CUS or wholeleg CUS must be chosen (13).

\section{Acknowledgments}

Funding: None.

\section{Footnote}

Conflicts of Interest: All authors have completed the ICMJE uniform disclosure form (available at http://dx.doi. org/10.21037/qims-2020-18). The authors have no conflicts of interest to declare.

Open Access Statement: This is an Open Access article distributed in accordance with the Creative Commons Attribution-NonCommercial-NoDerivs 4.0 International License (CC BY-NC-ND 4.0), which permits the noncommercial replication and distribution of the article with the strict proviso that no changes or edits are made and the original work is properly cited (including links to both the formal publication through the relevant DOI and the license). See: https://creativecommons.org/licenses/by-nc-nd/4.0/.

\section{References}

1. Kahn SR, Comerota AJ, Cushman M, Evans NS, Ginsberg JS, Goldenberg NA, Gupta DK, Prandoni P, Vedantham S, Walsh ME, Weitz JI; American Heart Association Council on Peripheral Vascular Disease, Council on Clinical Cardiology, and Council on Cardiovascular and Stroke Nursing. The postthrombotic syndrome: evidencebased prevention, diagnosis, and treatment strategies: a scientific statement from the American Heart Association. Circulation 2014;130:1636-61.

2. Bates SM, Jaeschke R, Stevens SM, Goodacre S, Wells PS, Stevenson MD, Kearon C, Schunemann HJ, Crowther M, Pauker SG, Makdissi R, Guyatt GH. Diagnosis of DVT: Antithrombotic Therapy and Prevention of Thrombosis, 9th ed: American College of Chest Physicians Evidence-
Based Clinical Practice Guidelines. Chest 2012;141:e351S-418S.

3. Talbot SR. B-mode evaluation of peripheral veins. Semin Ultrasound CT MR 1988;9:295-319.

4. Kearon C, Julian JA, Newman TE, Ginsberg JS. Review: Noninvasive tests are useful only for symptomatic deep venous thrombosis. ACP J Club 1998;129:46.

5. Stevens SM, Elliott CG, Chan KJ, Egger MJ, Ahmed KM. Withholding anticoagulation after a negative result on duplex ultrasonography for suspected symptomatic deep venous thrombosis. Ann Intern Med 2004;140:985-91.

6. Schellong SM, Goldhaber SZ, Weitz JI, Ageno W, Bounameaux H, Turpie AGG, Angchaisuksiri P, Haas S, Goto S, Zaghdoun A, Farjat A, Nielsen JD, Kayani G, Mantovani LG, Prandoni P, Kakkar AK. Isolated Distal Deep Vein Thrombosis: Perspectives from the GARFIELD-V'TE Registry. Thromb Haemost 2019;19:1675-85.

7. Righini M, Bounameaux H. Clinical relevance of distal deep vein thrombosis. Curr Opin Pulm Med 2008;14:408-13.

8. Barco $\mathrm{S}$. What's the matter with distal deep vein thrombosis? Thromb Haemost 2019;19:1547-9.

9. Johnson SA, Stevens SM, Woller SC, Lake E, Donadini M, Cheng J, Labarère J, Douketis JD. Risk of deep vein thrombosis following a single negative whole-leg compression ultrasound: a systematic review and metaanalysis. JAMA 2010;303:438-45.

10. Stevens SM, Woller SC, Graves KK, Aston V, Jones J, Snow G, Elliott CG. Withholding anticoagulation following a single negative whole-leg ultrasound in patients at high pretest probability for deep vein thrombosis. Clin Appl Thromb Hemost 2013;19:79-85.

11. Righini M, Robert-Ebadi H, Glauser F, Blondon M, Ouvry P, Diamand JM, Tissot A, Frappe P, Quere I, Kahn SR, Galanaud JP, Le Gal G. Effect of anticoagulant treatment on pain in distal deep vein thrombosis: an ancillary analysis from the cactus trial. J Thromb Haemost 2019;17:507-10.

12. Cogo A, Lensing AW, Wells P, Prandoni P, Büller HR. Noninvasive objective tests for the diagnosis of clinically suspected deep-vein thrombosis. Haemostasis 1995;25:27-39.

13. Lim W, Le Gal G, Bates SM, Righini M, Haramati LB, Lang E, Kline JA, Chasteen S, Snyder M, Patel P, Bhatt M, Patel P, Braun C, Begum H, Wiercioch W, Schünemann HJ, Mustafa RA. American Society of Hematology 2018 guidelines for management of venous thromboembolism: diagnosis of venous thromboembolism. Blood Adv 
2018;2:3226-56.

14. Birdwell BG, Raskob GE, Whitsett TL, Durica SS, Comp PC, George JN, Tytle TL, McKee PA. The clinical validity of normal compression ultrasonography in outpatients suspected of having deep venous thrombosis. Ann Intern Med 1998;128:1-7.

15. Kraaijpoel N, Carrier M, Le Gal G, McInnes MDF, Salameh JP, McGrath TA, van Es N, Moher D, Büller HR, Bossuyt PM, Leeflang MMG. Diagnostic accuracy of three ultrasonography strategies for deep vein thrombosis of the lower extremity: a systematic review and meta-analysis. PLoS One 2020;15:e0228788.

16. Kraaijenhagen RA, Piovella F, Bernardi E, Verlato F, Beckers EA, Koopman MM, Barone M, Camporese G, Potter Van Loon BJ, Prins MH, Prandoni P, Büller HR. Simplification of the diagnostic management of suspected deep vein thrombosis. Arch Intern Med 2002;162:907-11.

Cite this article as: Stevens SM, Fazili M, Woller SC. Choosing ultrasound technique for suspected deep vein thrombosis: which is best? Quant Imaging Med Surg 2020;10(6):1418-1421. doi: 10.21037/qims-2020-18 